\title{
UM ESTUDO DA IMPLEMENTAÇÃO DE MUDANÇAS SINTÁTICAS NO PORTUGUÊS BRASILEIRO: A ANÁLISE DE DADOS ESCRITOS
}

\author{
Juliana Costa Moreira* \\ Elaine Chaves*
}

Resumo: Estudos diacrônicos têm identificado o final do século do XIX como um momento em que mudanças sintáticas foram implementadas no português brasileiro (PB). Alguns desses estudos foram listados por Tarallo (1993) e por meio deles o autor concluiu que o final do século XIX foi o período em que surgiu a gramática do $\mathrm{PB}$. Apresentamos os resultados de outros dois estudos que se enquadram nesse perfil (CHAVES, 2006; MOREIRA, 2008) e utilizam amostras escritas como fonte de dados, no intuito de mostrar que os resultados podem ser interpretados de outro modo. Argumentamos que mudanças descritas a partir de dados escritos não se implementaram no período apontado, mas anteriormente. Nesse sentido, por extensão, sugerimos que o final do século XIX não é o período em que emerge a gramática do PB. Esse é o momento em que essa gramática se massifica no domínio da escrita, uma vez que inovações linguísticas tornamse visíveis na escrita quando são bem aceitas na fala.

Palavras-chave: Implementação linguística; língua escrita; gramática; português brasileiro; século XIX

* Universidade Federal de Minas Gerais. 


\begin{abstract}
Diachronic studies have shown that the end of the 19th century is a period in which syntactic changes were implemented in Brazilian Portuguese (BP). Some of these studies were listed by Tarallo (1993), arguing that the end of the 19th century was the period that witnessed the emergence of BP grammar. We present the results of two other studies that share the same profile (CHAVES, 2006; MOREIRA, 2008), in which written samples were analysed, in order to show that the results can be interpreted in a different way. We argue that the changes evidenced by the written samples analysis had been implemented in a previous period. It is our assumption that the end of the 19th century is not the period that witnessed the emergence of BP grammar. This period corresponds to the massification of grammar in written language, since linguistic innovations manifest in written language when they are accepted in oral language by speakers.
\end{abstract}

Keywords: Linguistic implementation; written language; grammar; Brazilian Portuguese; 19th century.

\title{
1. Introdução
}

O objetivo deste trabalho é mostrar um caminho possível para entender a implementação de mudanças sintáticas como fonte para a identificação de uma gramática do português brasileiro (doravante, $\mathrm{PB}$ ) distinta de uma gramática do português europeu (doravante, PE).

Muitos trabalhos têm identificado o final do século do XIX e o início do século XX como um momento em que mudanças sintáticas foram implementadas no PB. Em Tarallo (1993), encontra-se um estudo de encaixamento linguístico, nos termos de Weinrich, Herzog \& Labov (1968), em que o autor, baseando-se nos resultados apresentados por Tarallo $(1983,1985)$, Berlinck $(1988,1989)$, Ramos (1989, 1991) e Duarte (1992), afirma que as mudanças ocorridas entre os séculos XIX e XX marcam a emergência de "uma nova gramática radicalmente diferente da modalidade lusitana" (TARALLO, 1993, p. 99). Aponta ainda o final do século XIX como o momento da emergência dessa gramática, pois é nesse período em que se verifica 
a implementação de inúmeras mudanças sintáticas que vêm sendo tratadas na literatura como definidoras do PB. Vários são os estudos, em diferentes linhas de trabalho, analisando diversos fenômenos linguísticos, que corroboram a importância dessa data para a identificação da gramática do PB.

Neste trabalho, apresentaremos dois estudos que se enquadram no perfil identificado por Tarallo (1993), não apenas para endossar o perfil brevemente exposto nesse texto, mas para avançar, mostrando que esses resultados podem ser interpretados de outra maneira. A nossa proposta é que o final do século XIX não é o período em que emerge a gramática do $\mathrm{PB}$, ou seja, a gramática não mudou nesse momento, mas em momento anterior. Esse é o momento em que essa gramática se massifica no domínio da escrita.

Nesse sentido, o maior acesso à escrita proporcionou as circunstâncias sociais necessárias para que "a pena brasileira pudesse escorrer a própria tinta" (TARALLO, 1993, p. 99). Não estaríamos tratando da emergência da gramática do $\mathrm{PB}$, mas, sim, da amplificação na escrita.

Apresentaremos dois argumentos que mostrarão a validade da nossa hipótese. No primeiro, sugerimos que fenômenos da linguagem em uso são incorporados na língua escrita quando já são bem aceitos pelos falantes e se encontram na fala há muito tempo. Sugerimos, assim, que a mudança da ordem do vocativo na oração do PB, identificada por Moreira (2008), assim como as outras mudanças citadas, não ocorreram no período indicado para a implementação da gramática do $\mathrm{PB}$, ou seja, no fim do século XIX, mas sim anteriormente. No segundo, partindo do trabalho de Chaves (2006), que se dedica à contribuição das pistas gráficas para a compreensão de fenômenos linguísticos, mostraremos que o perfil das mudanças que atingem primeiramente a fala é o mesmo descrito para fenômenos que atingem a escrita.

Para o desenvolvimento do que foi proposto, adotamos uma possível inter-relação entre uma teoria da mudança e uma teoria da linguagem. Alguns autores que consideram possível esta conciliação (WEINRICH, LABOV \& HERZOG,1968; CHOMSKY, 
2000; LIGHTFOOT, 1991, 1999 apud KROCH, 2001; TARALLO \& KATO, 1989).

Segundo Weinreich, Labov \& Herzog (1968), um refinamento na teoria da linguagem tem consequências não só na postulação/ formulação dos fatores linguísticos que impulsionam uma mudança, mas no próprio elenco das mudanças postuladas.

Tarallo \& Kato (1989) compartilham desse ponto de vista e propõem um modelo que concilia a sociolinguística variacionista com a gramática gerativa. Essa proposta defende que a variação sincrônica inter-linguística e a variação diacrônica intra-linguística são alterações decorrentes dos mesmos princípios gerais. Assim, os mesmos princípios e parâmetros deveriam dar conta da variação inter-linguística e intra-linguística, e os conceitos de encaixamento estrutural e parâmetro poderiam ser conciliados - cf. Princípio do Uniformitarismo (LABOV, 1972, p. 161 e 1982, p. 20). ${ }^{1}$

Lightfoot (1991, 1999) apud Kroch (2001) leva em consideração que o método histórico e o método gerativo se complementam. $\mathrm{O}$ autor considera que os dois tipos de mudança são dependentes do tempo, mas em dois caminhos diferentes. Assim, linguistas diacrônicos podem descrever as gramáticas da língua com o mesmo método e com as mesmas ideias de linguistas sincrônicos gerativistas ("nós podemos descrever a gramática antes e depois da mudança") através da comparação e análise das diferentes gramáticas.

Para Chomsky (2000), a mudança diacrônica deve estar conectada ao espraiamento de mudanças, tomando lugar através de muitas gerações, uma vez que deve ser conectada à linguagem em uso. Nessa linha de raciocínio, consideramos que a língua em uso pode se desenvolver gradualmente em várias gerações, até que, em um dado momento, o uso da língua não reflete mais a gramática subjacente, ocorre, então, mudança na gramática do falante.

\footnotetext{
${ }^{1}$ Entre os estudos em que a proposta de conciliação destes dois modelos de análise linguística tem estado subjacente, encontra-se o de Ramos (1991), que contribui de maneira significativa para a explicitação e desenvolvimento dessa proposta.
} 
Posto isso, discorreremos, na próxima seção, sobre o tratamento que tem sido dispensado ao processo de mudança linguística em diferentes perspectivas, para em seguida apresentarmos as análises feitas por Moreira (2008) e Chaves (2006).

\section{A mudança linguística em diferentes perspectivas}

Weinreich, Labov \& Herzog (1968) identificam a mudança como a face sincrônica da variação. Através de evidências obtidas em uma análise sincrônica, podem-se diagnosticar mudanças ocorridas no passado, o que permite o estudo diacrônico de um determinado fenômeno linguístico. Desse modo, conhecimentos adquiridos através da mudança em progresso podem ser generalizados para as mudanças já terminadas utilizando-se o Princípio do Uniformitarismo (LABOV, 1972, p. 161 e 1982, p. 20), segundo o qual os mesmos mecanismos que propiciaram uma mudança no presente podem ser os que atuam no passado.

Este princípio faz-nos compreender que há certa regularidade no efeito de fatores controladores da variação e, portanto, há grandes possibilidades de que variações diagnosticadas no PB atual estejam presentes no português desde as suas origens. Assim, se é verdade que a compreensão dos fatos passados auxilia na compreensão dos fatos do presente, é bem verdade também que o presente pode elucidar processos de mudanças em andamento ou até mesmo concluídos.

No plano sincrônico, o objeto do modelo variacionista é o estudo da língua falada em seu contexto real de uso, o que somente se faz possível a partir do vernáculo, estilo em que o mínimo de atenção é dada à fala. Já no plano diacrônico, deparamo-nos com um problema: a ausência de falantes da língua representativa de períodos passados. Faz-se necessário, então, analisar documentos representativos do(s) período(s) de tempo em estudo.

Outra dificuldade é encontrar textos confiáveis capazes de retratar ou de se aproximar da língua utilizada àquela época. 
Como Labov (1994) afirma, os textos que retratam períodos antigos da língua são sempre repletos de lacunas. Estruturas que sobrevivem nos textos escritos podem constituir resultado de um esforço em direção à norma culta escrita, o que significa uma filtragem das formas linguísticas e mesmo hipercorreção. Isso faz com que muitas vezes sejam observadas nos textos formas que há muito tempo desapareceram da fala.

Esses problemas podem limitar as conclusões a partir do estudo de um determinado fenômeno linguístico. Entretanto, recorrer aos textos representativos de um dado período de tempo é válido por constituir o único meio para trilhar os caminhos percorridos por um sistema linguístico. Para Labov (1994), no estudo diacrônico da variação linguística, desenvolve-se a "arte de fazer bom uso de maus dados". É tarefa árdua encontrar textos que reflitam a língua dos falantes de uma determinada época. Os pesquisadores podem se valer de alguns cuidados na tentativa de minimizar estas dificuldades a ponto de reunir dados confiáveis ao estudo linguístico. O que se faz geralmente é controlar o gênero textual: é adequado o uso de cartas de cunho pessoal e/ou peças de teatro, uma vez que, nesses textos, podemos encontrar a expressão da língua dos falantes de um determinado período de tempo em uma situação de menor formalidade ou de formalidade reconhecida. ${ }^{2}$

A partir da utilização desse método, o linguista consegue reunir dados suficientes representativos do vernáculo de uma determinada sincronia. Apesar de esses dados nos permitirem descrever a gramática utilizada pelo falante de uma língua, não é possível obter informações a respeito de como a gramática foi adquirida. Recorremos, assim, aos estudos que versam sobre a relação existente entre a mudança linguística e a aquisição da linguagem.

Segundo Bailey et al. (1991, p. 242), a fala de cada geração reflete a língua do momento em que esta geração a adquiriu. Como Chambers \&Trudgill (1980, p. 165) observam, a fala de uma

${ }^{2}$ Para mais detalhes, ver Chaves \& Moreira (2006). 
pessoa de 40 anos hoje reflete a fala de vinte anos atrás. Atribui-se esse fato ao progresso da inovação linguística.

Já Lightfoot $(1991,1999)$ considera que os aprendizes prestam atenção somente nos gatilhos, que são propriedades sintáticas que definem os parâmetros, presentes nas sentenças matrizes/principais. Assim, as línguas podem mudar a partir de desvios nas frequências de uso dos vários tipos de sentenças. Essa distorção de frequências se torna tão marcada que os aprendizes não são expostos a dados cruciais e, assim, adquirem uma gramática diferente das gerações anteriores. ${ }^{3}$

Considera-se que mudanças começam com uma mudança na gramática e essa mudança gramatical interfere na frequência com que certas formas são usadas. A mudança é, assim, determinada pelos tipos de desvios que os aprendizes são capazes de cometer, $o$ que causa imprecisão na transmissão da língua. A questão que tem sido colocada é: como a criança consegue adquirir a língua em tão pouco tempo com tão poucos dados ou com dados tão imperfeitos?

Kroch (2001) critica o ponto de vista de Lightfoot: como as evidências vão mudar se o parâmetro ainda não mudou? É inconcebível, para ele, que uma mudança ocorra tão rapidamente.

Para Hróarsdóttir (2003), a aquisição da linguagem é definida como um processo em que a Gramática Universal (GU) interage com um conjunto de dados linguísticos, o input avaliável para a criança durante o processo de aquisição da linguagem em um contexto específico. A criança tem acesso aos Dados Linguísticos Primários (DLP), à língua falada pelos pais e pelas pessoas do convívio desta. Esses dados são utilizados como um recurso para ativar seu conhecimento inato e para a maturação da gramática e são relevantes, portanto, para o acionamento dos parâmetros.

Essa definição está em concordância com a afirmação de Kroch (2001) de que a aquisição bem sucedida da sintaxe de uma

\footnotetext{
${ }^{3}$ Se encontra evidência disponível, o aprendiz mapeia corretamente, mas, quando o gatilho é raro, o parâmetro é fixado erroneamente.
} 
língua depende claramente da interação das suas propriedades estruturais com a característica do aprendiz. Para o autor, a variação ocorre no output dos adultos, não na gramática dos adultos; o que muda é a gramática das crianças.

Segundo Kroch (2001), a mudança linguística é, então, por definição, uma falha na transmissão de traços através do tempo. Tais falhas parecem ocorrer no curso da aquisição da linguagem; são falhas no aprendizado. Uma vez que, numa instância de mudança sintática, o traço que o aprendiz falha em adquirir é passível de ser aprendido em princípio, tendo sido parte da gramática da língua num passado imediato, a causa da falha deve recair em alguma mudança, talvez sutil, no tipo de evidência disponível para o aprendiz ou em alguma diferença, por exemplo, na sua idade durante o processo de aquisição, como no caso da mudança induzida através de contato linguístico. ${ }^{4}$

Para ele, então, a mudança sintática consiste em uma reanálise gramatical abrupta que ocorre quando uma nova geração adquire a língua. A mudança em outros níveis de estrutura, como quer que tenha sido causada, provoca uma reanálise gramatical: há uma relação causal entre as mudanças, e, assim, uma mudança no nível morfo-fonológico pode levar a uma mudança no nível sintático simplesmente pela evidência disponível ao aprendiz. ${ }^{5}$

\footnotetext{
${ }^{4}$ Ressalta-se, no entanto, que o nosso entendimento de falhas na transmissão é muito limitado, porque a nossa compreensão da relação entre a evidência apresentada ao aprendiz e a gramática adquirida ainda é imprecisa. Os estudos de aquisição da linguagem, geralmente, tomam por certo que a evidência a que o aprendiz é exposto é suficiente para garantir uma aprendizagem precisa por parte de um aprendiz competente, isto é, uma criança na sua idade crítica. Para o autor, essa suposição é perfeitamente razoável, mas há limites para a sua validade.

${ }^{5}$ De acordo com essa concepção, a mudança não existe na língua (mudança endógena), mas é inferida pelas pessoas, sendo despida da noção de deriva, segundo a qual a língua é independente das pessoas que a falam. Uma proposta gerativa que permite a mudança sintática endógena, ou seja, que a mudança é inerente à sintaxe é a de Andersen (1973) apud Kroch (2001).
} 
Um exemplo ilustrativo fornecido pelo autor é o de que a perda da distinção morfológica no sistema de casos devido a um enfraquecimento fonológico na terminação das palavras é geralmente pensada como o que leva a uma rigidez na ordem das palavras (para compensar a ambiguidade induzida pela perda de casos). Assim, há línguas como o holandês, que perderam suas terminações de caso e têm praticamente uma ordem fixa das palavras, enquanto línguas como alemão, que mantiveram um sistema de quatro casos distintos, permitem o ordenamento livre de constituintes.

Além disso, Kroch (2001) considera que a frequência com que as formas linguísticas são utilizadas é resultado da competição de gramáticas. ${ }^{6}$ Em uma situação de contato com outra comunidade de fala, as pessoas vão ouvir expressões de uma e de outra comunidade. ${ }^{7}$ A criança estará exposta a parâmetros diferentes e fará uma escolha.

A noção de competição é formulada ainda em relação à diglossia sintática, no sentido que formas em competição se fazem presentes no registro social com uma variante vernacular lentamente guiando uma variante escrita fora do uso. $O$ autor caracteriza cada estilo/registro como uma gramática diferente, o que leva a considerar que tanto o falante quanto a comunidade são bidialetais.

\section{A mudança diacrônica descrita a partir de dados escritos}

\subsection{Vocativo}

Moreira (2008) analisou o fenômeno sintático da ordem do vocativo na oração do $\mathrm{PB}$, considerando que esse sintagma pode ser, assim, distribuído:

\footnotetext{
${ }^{6}$ Para ele, a língua só muda quando há competição de gramáticas.

${ }^{7}$ Para Kroch (2003, p. 24), "uma força atuante para a mudança sintática, cuja força não pode ser posta em dúvida é o contato linguístico."
} 
(1) Posição inicial na oração [Voc + Or]

Emília, há muito tempo que observo este teu padrasto. (PENA, 1956, p. 300)

(2) Posição final [Or + Voc]

Hoje não é dia de falar de coisas tristes, Vado. (MARCOS, 1978, p. 90)

(3) Posição medial [Or + Voc + Or]

Deus, senhores, não se compraz com sacrifícios alheios. (PENA, 1956, p. 316)

O corpus do qual os exemplos acima foram extraídos é constituído por diálogos de peças teatrais escritas nos séculos XIX e $\mathrm{XX}$. Essa escolha justifica-se pelo fato de serem textos que mais se aproximam da modalidade oral da língua, uma vez que tendem a ser a representação da fala da personagem. A escolha deveu-se ainda ao fato de, nesses textos, existir um número considerável de construções com vocativo para a realização de uma análise quantitativa. Lembramos que a construção com vocativo emerge em situações de interlocução (discurso direto). Para evitar que textos que tiveram edições atualizadas fossem analisados, as edições foram selecionados com o máximo de rigor possível. Assim, buscaram-se as edições mais antigas de cada obra, ou ainda, quando possível, o original manuscrito.

Os dados recolhidos totalizam 1420 construções contendo vocativos, os quais foram submetidos ao Goldvarb (2001).

Verificou-se que as construções com vocativo em posição final (55\%) são mais produtivas do que com vocativo em posição inicial e com posição medial, que representaram, respectivamente, $36 \%$ e $9 \%{ }^{8}$ A distribuição das estruturas com vocativo do referido corpus em relação ao período de tempo em que foram escritas são apresentadas a seguir: ${ }^{9}$

\footnotetext{
${ }^{8}$ Ao considerar a baixa frequência da ordem [Or + Voc + Or], essas construções foram descartadas, no que se refere à análise quantitativa realizada, uma vez que tal análise é feita a partir de uma variável binária.

${ }^{9} \mathrm{~T} 1$ corresponde à $1^{\mathrm{a}}$ metade do século XIX, T2 à $2^{\mathrm{a}}$ metade do século XIX, T3 à $1^{\mathrm{a}}$ metade do século XX e T4́ à $2^{\mathrm{a}}$ metade do século XX.
} 
TABELA 1

Taxa de uso das ocorrências de vocativo em função do tempo ${ }^{10}$

\begin{tabular}{|c|c|c|c|c|c|c|c|c|c|c|c|c|c|}
\hline Estruturas & & T1 & & & T2 & & & T3 & & & T4 & & Total \\
\hline & $\mathrm{N}^{\mathrm{o}}$ & $\%$ & PR & $\mathrm{N}^{\mathrm{o}}$ & $\%$ & PR & $\mathrm{N}^{\mathrm{O}}$ & $\%$ & PR & $\mathrm{N}^{\mathrm{o}}$ & $\%$ & PR & \\
\hline$[\mathrm{Voc}+\mathrm{Or}]$ & 160 & 43 & .61 & 114 & 46 & .56 & 131 & 35 & .43 & 106 & 36 & .39 & 511 \\
\hline$[\mathrm{Or}+\mathrm{Voc}]$ & 209 & 57 & .38 & 133 & 54 & .43 & 245 & 65 & .57 & 189 & 64 & .60 & 776 \\
\hline Total & 369 & 100 & - & 247 & 100 & 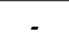 & 376 & 100 & - & 295 & 100 & - & 1287 \\
\hline
\end{tabular}

A comparação dos resultados mostra perfis diferentes entre as construções contendo vocativos, o que sugere estar havendo competição entre estas construções em todos os períodos de tempo analisados.

O perfil apresentado pela construção [Or + Voc] (com base nos pesos relativos) pode ser visualizado no Gráfico 1, a seguir:

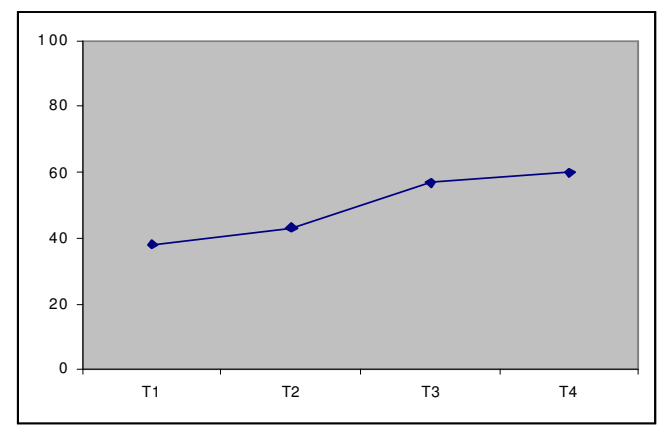

GRÁfICO 1: Efeito do fator tempo sobre o uso da construção [Or + Voc]

A construção [Or + Voc] apresenta perfil ascendente, com maior índice de ocorrência em T4. Observe-se que esse perfil mostra uma curva em $S$, sendo, portanto, indicativo de mudança linguística.

A ideia de que a mudança linguística segue uma curva em $S$ ao longo do tempo é sugerida por Weinreich, Labov \& Herzog

${ }^{10} \mathrm{PR}=$ Peso Relativo. 
(1968), por Bailey (1973) e, mais recentemente por Altman et al. (1983). De acordo com essa ideia, a forma inovadora substitui a primeira, inicialmente, de forma devagar e, nos estágios médio e final, a substituição se dá de maneira acelerada, de modo que as formas conservadoras se tornam raras.

Kroch (2001), no entanto, considera que a curva em $S$ apresenta um perfil ilusório, uma vez que reflete uma mudança no uso da língua e não uma mudança na gramática. Como vimos, a mudança linguística é concebida pelo autor como uma falha na transmissão de traços através do tempo. Sendo assim, as crianças nem sempre adquirem a gramática alvo da língua a que elas estão expostas. Para o autor, a evidência disponível para a fixação de um dado parâmetro pode se tornar tão rara que alguns aprendizes podem ser expostos a dados não suficientes para fixá-lo corretamente. $\mathrm{O}$ resultado será uma comunidade na qual alguns falantes tenham a fixação do parâmetro antigo, e outros, a nova. Uma vez que uma comunidade se torna diglóssica com relação à fixação paramétrica, todo falante vai aprender ambos os parâmetros. ${ }^{11}$ Assim, a frequência com que certas formas são utilizadas é resultado da competição de gramáticas. ${ }^{12}$

Provavelmente, a próxima geração de aprendizes será menos exposta a dados necessários para a fixação do parâmetro antigo. Efetiva-se, então, a mudança de uma gramática para outra, o que corresponde a uma reanálise gramatical abrupta. ${ }^{13} \mathrm{Um}$

${ }^{11}$ De acordo com Kroch (2001), a escolha de qual critério de boa formação deva ser adotado não é questão para a teoria gramatical, pois é do domínio da performance.

${ }^{12}$ A noção de competição de gramáticas é formulada a partir da diglossia sintática ou do contato linguístico.

${ }^{13}$ Para Kroch, a mudança sintática consiste em uma reanálise gramatical abrupta que ocorre quando uma nova geração de falantes adquire a língua. A mudança em outros níveis de estrutura, como quer que tenha sido causada, provoca uma reanálise gramatical. 
exemplo de mudança na gramática, citado por Kroch (2001), é a do aparecimento do do perifrástico registrado por Ellegård (1953).

O Gráfico 2 a seguir mostra o aumento da frequência da construção [Or + Voc] ao longo do tempo (com base nos pesos relativos) e, ainda, a transformação logística da frequência de uso, calculada para essa construção em cada período de tempo analisado. ${ }^{14}$

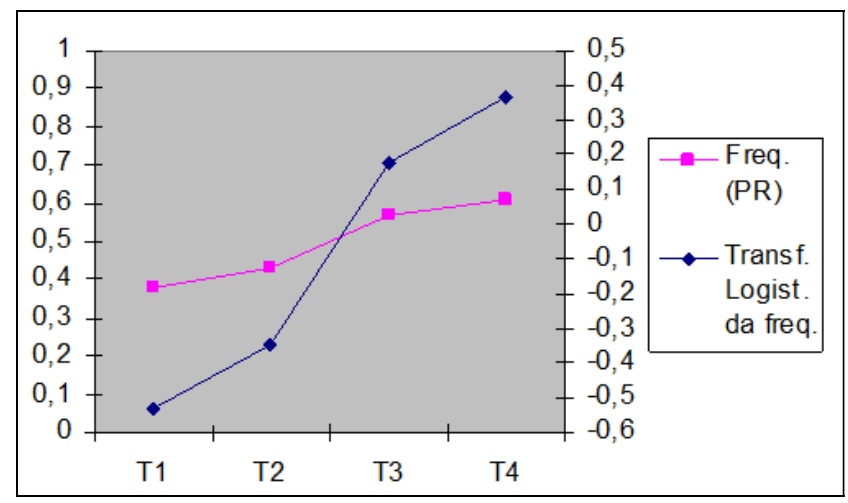

GRÁFICO 2: Aumento da estrutura [Or + Voc] no português brasileiro

O gráfico acima nos permite observar que a mudança no uso da língua, ou seja, a mudança da ordem do vocativo na oração, ilustrada por um perfil de curva em $S$, leva a uma mudança no nível abstrato (gramática). Como se pode ver, a curva referente à transformação logística da frequência ${ }^{15}$ também exibe um perfil de curva em $S$.

${ }_{14} \mathrm{~T} 1$ corresponde à $1^{\mathrm{a}}$ metade do século XIX, T2 à $2^{\mathrm{a}}$ metade do século XIX, T3 à $1^{\mathrm{a}}$ metade do século XX e T4 à $2^{\mathrm{a}}$ metade do século XX.

${ }^{15} \mathrm{~A}$ transformação logística da frequência é uma função linear no tempo, resultante de equações que permitem analisar mudanças que apresentam perfil de curva em $S$ respondendo com precisão questões relativas à evolução da mudança no tempo. Trata-se de um modelo matemático criado por Kroch (1989), no qual as suas equações são formadas pelas variáveis $p, t, s$ e $k$. $p$ é a frequência da forma inovadora (pode variar entre 0 e 1); $t$ é o tempo variável; $s$ e $\boldsymbol{k}$ são constantes. A constante $s$ é o desvio (slope) e representa a taxa de substituição da forma inovadora pela conservadora. 
Desse modo, pode-se dizer que a mudança linguística, relativa à mudança na frequência de uso da construção [Or + Voc], é resultado da competição de gramáticas. De acordo com a curva referente à transformação logística da frequência no gráfico, o aumento da construção [Or + Voc] fica mais rápido no recorte de tempo que vai da segunda metade do século XIX (T2) até a primeira metade do século XX (T3). Podemos observar o mesmo através da curva referente às frequências de uso da construção [Or + Voc]. Já havíamos observado que a preferência por esta construção começa a acontecer na segunda metade do século XIX, ao analisar os resultados referentes ao aumento da frequência de uso da construção $[\mathrm{Or}+\mathrm{Voc}] .^{16}$

Na primeira metade do século XX (T3), as duas curvas se encontram. Nesse ponto, dá-se a reanálise das construções contendo vocativo, processo que ocorre, de acordo com Kroch (2001), quando uma nova geração de falantes adquire a língua. Ao tratar da reanálise, Moreira (2008) observa que a mudança sintática identificada na língua em uso (mudança no output dos adultos) leva à uma mudança na gramática da nova geração de falantes do PB. ${ }^{17}$

Os resultados apresentados por Moreira (2008) são representativos do perfil descrito por vários outros estudos sobre implementação de mudanças no século XIX, que utilizam amostra

\footnotetext{
Assim temos: $s=p n-p n-1, n=1,2,3, \ldots, n-1 . k$ é o parâmetro de interseção que mede a frequência da forma inovadora no ponto de tempo fixo $(t=0)$. Para um dado valor de $s$, a curva tem uma forma fixa. Mudando o ponto no tempo, teremos alteração no valor de $k$, que é obtido através da equação citada e pode variar entre +8 e -8 e $p$ pode variar entre 0 e 1 , mas não pode ser igual a 0 e 1 .

${ }^{16}$ Note-se, ainda, que a mudança identificada aqui não está ainda completada. ${ }^{17}$ Uma vez identificado um perfil de curva em $S$, indicativo de mudança na língua em uso, Moreira (2008) aplicou o modelo matemático (KROCH, 1989). A partir da utilização desse modelo, de acordo com o autor, é possível verificar se a mudança diagnosticada é resultado da competição de gramáticas e, por conseguinte, se é refletida na gramática do PB.
} 
escrita para obtenção de dados. Como mencionado, nesses trabalhos os dados escritos são utilizados como representativos da fala de períodos passados da língua.

Embora não fosse a intenção da autora tratar da incorporação da construção [Or + Voc] na escrita, é possível depreender esta leitura dos seus resultados. Nessa perspectiva, sugerimos que o ponto indicativo de reanálise nos gráficos apresentados é demostrativo da incorporação de tal ordem na escrita, o que sucedeu por esta ser bem aceita na fala. Sugerimos que a implementação dessa ordem na fala se deu em momento anterior ao indicado. Esse momento corresponde a sua incorporação na escrita. Isto permite-nos supor que a gramática do PB não emerge nesse momento, mas em momento anterior.

É importante deixar claro, no entanto, que a única maneira de depreendermos a língua representativa da modalidade oral de sincronias passadas é a partir da utilização dos dados escritos. Como foi dito, recorrer aos textos representativos de um dado período de tempo é válido por constituir o único meio para trilhar os caminhos percorridos por um sistema linguístico.

Tendo em vista o exposto, consideramos que os resultados dos trabalhos que utilizam textos escritos como representativos de períodos passados da língua devem ser avaliados sob duas perspectivas: uma delas toma esses dados como representativos da fala; a outra os aborda como representativos da escrita. A primeira pespectiva de análise foi desenvolvida no estudo de Moreira (2008), assim como nos outros estudos citados por Tarallo (1993). A nossa tentativa, neste trabalho, é lançar um olhar em direção à segunda, considerando que um caminho interessante para entender a implementação de mudanças sintáticas no PB seria a inter-relação das duas perspectivas de análise.

\subsection{Vossa Mercê > Você}

Chaves (2006) investigou a contribuição das pistas gráficas para o estudo de implementação de mudanças. Observando um fenômeno que tem Vossa Mercê como ponto de partida e Você 
como ponto de chegada, demonstrou que um fenômeno gráfico que pode contribuir para os estudos de fenômenos linguísticos. A seguir, alguns exemplos dos dados utilizados pela autora:

(4) Estimo que vm e tudo quanto be noco esteje no gozo deperfeita saúde eigual o meu dezejo (1872)

(5) enconçiençia que $\mathrm{Vm}^{\text {ce }}$ bade ter susego (1874)

(6) que $V^{c e}$ queira me lançar a sua benção (1825)

(7) Arlindo você mesmo não imagina como eu fiquei (1904)

(8) Tenbo sido incorreto para com $V^{\text {ce }}$. (1907)

(9) So pesso que pegue com N. Senr ${ }^{\circ}$ e S. Geraldo para VC ser feliz. (1908)

(10) eu ser as orações que VM empregar a Nossa Mãe de Deus (1852)

Os dados foram recolhidos em corpora constituídos por cartas pessoais, datadas, assinadas e com remetente e destinatário identificados, da primeira e da segunda metade do século XIX e da primeira metade do século XX. Essa amostra foi assim constituída por serem as cartas pessoais um subgênero textual em que o fenômeno investigado é recorrentemente utilizado. $\mathrm{O}$ estudo teve como arcabouço teórico-metodológico a linguística histórica e a sociolinguística variacionista.

Inicialmente, Chaves (2006) observou as abreviaturas da forma Vossa Mercê e da forma Você, porém, como para a realização da análise quantitativa o número de abreviaturas de Você era muito pequeno, optou por adotar como variável dependente a inicial maiúscula ou minúscula das abreviaturas e formas plenas de tais itens. A escolha desse fenômeno se deveu: (1) ao fato de o estudo priorizar a escrita; (2) ao fato de a expressão linguística do informante ser moldada de acordo com o interlocutor (tendo-se em conta a utilização de duas modalidades - oral e escrita - com sua autonomia e suas especificidades, considerou-se que a presença do interlocutor esteja expressa diferentemente em cada uma); (3) à recorrente menção na literatura de que as abreviaturas 
constituem algo assistemático; (4) à não datação dos estágios sintagma nominal > item lexical > pronome; e (5) ao fato de Fontanella de Weinberg (1994) ter afirmado que a datação acima referida não é possível porque o uso de formas abreviadas impede a documentação de cada um desses estágios.

Chaves (2006) partiu do pressuposto de que as escolhas gráficas não são aleatórias, mas resultam de condicionamentos. Dado o grande número de abreviaturas e sua alta frequência nos corpora avaliados e em diferentes gêneros textuais, colocou-se o desafio de rejeitar o caráter caótico desse tipo de ocorrência, e desvendar alguma sistematicidade no seu uso. Para além disso, buscou identificar o papel das pistas gráficas para o estudo linguístico.

Dos vários resultados obtidos pela autora, serão priorizados três que servirão de argumento para a interpretação proposta neste artigo, a saber: (i) as formas gráficas evoluem no eixo do tempo; (ii) há comprovação da sistematicidade no uso e composição das abreviaturas; e (iii) mesmo existindo formas abreviadas, as iniciais destas permitem datar estágios de gramaticalização.

Para alcançar (i), a autora mostrou que as abreviaturas não são indiferentes às transformações que afetam o item a que correspondem. Por meio do trabalho desenvolvido por Gonzalez (2002), que descreve o percurso histórico da abreviatura para New York, Chaves (2006) encontrou subsídios para propor um quadro evolutivo para as abreviaturas por ela encontradas. O quadro se sustenta em dois pilares: a capitalização das iniciais e a perda de diacríticos e pontuação. A autora notou que as abreviaturas de Vossa Mercê, com iniciais maiúsculas, não apresentam acentos e nem cedilhas, que as letras sobrescritas e os pontos abreviativos só desaparecem com o término da transformação do Vossa Mercê em Você e com a entrada do Você em sua forma plena. Ao mesmo tempo, notou-se que as iniciais maiúsculas, $V M$, passam para apenas uma inicial maiúscula, $V m$, e depois deixa de ser maiúscula e passa a ser inicial minúscula, vm. O mesmo acontece com Você, que, embora tenha em suas ocorrências o início com a letra minúscula, $v o^{c e}$, esta abreviatura com inicial minúscula poderia 
estar representando o estágio de transformação de Vossa Mercê em Você, pois, aparentemente, corresponderia ao vosm'cê > voscê. A observação dos estágios de transformação do Vossa Mercê em Você encontra respaldo na convenção feita no Vocabulário Ortográfico da Língua Portuguesa, da Academia Brasileira de Letras, que diz corresponder a forma abreviada $V m^{c e}$ a Vossa Mercê e a forma abreviada $v^{c e}$ a Vossemecê ou Vosmecê, variantes do pronome Vossa Mercê. Outra evidência desse fato é a existência da já referida forma abreviada $v o^{c e}$ (p. ex., "epeso avo ${ }^{c e}$ para medar um quarto" (cartas entre amigas, séc. XIX)) ser quase idêntica à forma plena do pronome Você.

O percurso histórico descrito para a composição das abreviaturas feito por Gonzalez (2002) e Chaves (2006) atesta a sistematicidade no uso e na composição das abreviaturas propostas em (ii). Esse fato torna-se ainda mais evidente ao considerarmos item (iii). A autora compõe uma tabela em que mostra o percurso do uso das iniciais maiúsculas e minúsculas. Observando os dados e separando-os de acordo com o período de tempo, constatou que as iniciais maiúsculas $V M$ deixam de ser usadas na primeira metade do século XIX; as abreviaturas com letra minúscula entram em uso neste mesmo século, porém a partir da segunda metade; e imediatamente após o desuso das letras minúsculas $v m$, temos a entrada do Você em sua forma plena, após a oscilação ou convivência ainda existente com as formas abreviadas do estágio anterior. Depois, com a finalização do estágio de $v m$ minúsculas, no início do século XX o próprio Você aparece abreviado inicialmente com letra maiúscula como ocorreu no surgimento da sua forma plena, e depois com letra minúscula. Com base nesses fatos, a autora considerou que as maiúsculas indicariam tratamento de cortesia e reverência e, portanto, uso não pronominal dos itens, e as letras minúsculas nas abreviaturas indicariam ausência de reverência e, portanto, uso pronominal dos itens.

No que diz respeito à extensão da abreviatura, que se define pela presença/ausência de ce sobrescrito, e ao testemunho de textos 
literários que apontam nesse período de tempo um uso sistemático do item Vosmecê, pode identificar os quatro estágios a seguir:

$$
\begin{aligned}
\text { (11) VM } & >V^{c e}>v^{c e}>v^{c e}>\text { você } \\
\text { Vossa Mercê } & >\text { Vossemecê }>\text { vosmecê }>\text { vancê }>\text { você }
\end{aligned}
$$

A identificação desses estágios comprovam também que o problema apontado por Fontanella de Weinberg (1994) não chega a impossibilitar a identificação dos estágios sintagma nominal $>$ item lexical $>$ pronome. Na verdade, constitui um recurso relevante na datação e mostra que as formas gráficas evoluem no eixo do tempo por não serem indiferentes às transformações que afetam o item.

\section{Conclusão}

Embora seja reconhecidamente uma tarefa exercida por todo pesquisador (linguista) tentar minimizar o efeito dos maus dados em sua investigações, como Labov (1994) afirma, os textos que retratam períodos antigos da língua são sempre repletos de lacunas. Estruturas que sobrevivem nos textos escritos podem constituir resultado de um esforço em direção à norma culta escrita, o que significa uma filtragem das formas linguísticas e mesmo hipercorreção. Isso faz com que muitas vezes sejam observadas nos textos formas que há muito tempo desapareceram da fala. Nesse sentido, os trabalhos sobre o PB, referenciados na introdução, não puderam suprir essas lacunas, seja por não ser esse o objetivo do estudo, seja por não terem à mão elementos suficientes para tanto.

Nos estudos de Chaves (2006) e Moreira (2008), tem-se uma forte evidência para se pensar que o século XIX é o momento em que a gramática do PB se manifesta na escrita. Esses estudos abrem possibilidade para pensar-se em uma questão: se a língua escrita é adquirida depois da língua falada, se se tem a fixação de parâmetros de uma gramática até aproximadamente os 14 anos do indivíduo, e, 
ainda, se pensarmos que, de acordo com Chambers \& Trudgill (1980), a fala de uma pessoa de quarenta anos reflete a gramática de vinte anos antes, podemos dizer que um fenômeno escrito apresenta $o$ mesmo perfil dos fenômenos de fala apresentados nos trabalhos sobre implementação de mudanças no século XIX?

A nossa resposta para essa pergunta é que um fenômeno linguístico só é bem aceito na escrita se ele não sofrer nenhum tipo de estigma na fala e nenhum tipo de restrição para o seu uso. Sendo assim, no que diz respeito ao estudo de Moreira (2008), podemos depreender que o uso da construção com vocativo em posição final, embora em competição com a construção com vocativo em posição inicial, já era bem aceita nos contextos de fala no século XIX e fora implementada na escrita ao final desse século. Do mesmo modo, em relação ao estudo de Chaves (2006), argumentamos que a forma Vossa Mercê, no século XIX, já era plenamente aceita e já se encontrava enfraquecida enquanto variante, uma vez que perdeu a competição para Você. Já a forma Você ainda não era aceita em todos os contextos de fala, como Vossa Mercê. Por essa razão, há um número muito pequeno de abreviaturas de Você, a maioria feita pelo mesmo interlocutor. As abreviaturas de Você serão mais frequentes no século XX.

Por fim, não deixando de considerar relevante a análise de corpora escritos como representativos da fala de sincronias passadas, sugerimos a análise desses dados também como representativos da própria escrita. A inter-relação entre essas duas perspectivas de análise pode trazer contribuições para uma melhor compreensão de fenômenos de mudança sintática e, porventura, indicar o momento em que emerge uma gramática do $\mathrm{PB}$, independente da gramática do PE. 


\section{Referências}

ALTMANN, G. H., VON BUTTLAR, W. R.; STRAUB, U. A law of change in language. In: BRAINERD, B. (Ed.). Historical linguistics. Bochum: Studienverlag Dr. N. Brockmeyer, 1983. p. 104-115.

ANDERSEN, H. Abductive and deductive change. Language, Baltimore, v. 49, p. 765-793, 1973.

BAILEY, C. J. Variation and linguistic theory. Washington, DC: Center for Applied Linguistics, 1973.

BAILEY, G.; WIKLE, T.; TILLERY, J.; SAND, L. The apparent time construct. Language Variation and Change, Philadelphia, v. 3, p. 241-264, 1991.

BERLINCK, R. de A. A ordem VS N no português do Brasil: sincronia e diacronia. Dissertação (Mestrado) - Universidade Estadual de Campinas, Campinas, 1988.

BERLINCK, R. de A. A construção V SN no português do Brasil: uma visão diacrônica do fenômeno da ordem. In: TARALLO, F. Fotografias sociolinguísticas. Campinas: Pontes, 1989. p. 95-112.

CHAMBERS, J.; TRUDGILL, P. Dialectology. Cambridge: Cambridge University Press, 1980.

CHAVES, E. A implementação de você: contribuição das pistas gráficas. Dissertação (Mestrado) - Universidade Federal de Minas Gerais, Belo Horizonte, 2006.

CHAVES, E.; MOREIRA, J. C. Coleta de dados em textos escritos: levantamento de dados e montagens dos corpora. In: SEMANA DE EVENTOS DA FACULDADE DE LETRAS DA UFMG, VI, Belo Horizonte, 16-20 outubro 2006. Anais... Belo Horizonte: Faculdade de Letras da Universidade Federal de Minas Gerais, 2006.

CHOMSKY, N. Minimalism inquiries: the framework. In: MARTIN, R.; URIAGEREKA, J. (Eds.) Step by step: essays on minimalism syntax in honor of Howard Lasnik. Cambridge, MA: MIT Press, 2000. p. 89-155.

DUARTE, M. E. L. A perda da ordem V (verbo) $\mathrm{S}$ (sujeito) em interrogativas QU- no português do Brasil. D.E.L.T.A, São Paulo, v. 8, n. esp., p. 37-52, 1992. 
ELLEGARD, A. The auxiliary do: the establishment and regulation of its use in English. Stockholm: Almqvist \& Wiksell, 1953.

FONTANELLA DE WEINBERG, M. B. Fórmulas de tratamiento en el español americano (siglos XVI y XVII). In: FONTANELLA DE WEINBERG, M. B. (Org.) El español en el nuevo mundo: estudios sobre historia lingüística hispanoamericana. Washington, DC: OEA/Colección INTERAMER, 1994. p. 1-15.

GONZÁLEZ, F. R. Variación tipográfica en el uso de las “abreviaturas”. Madrid, 2002. [Disponível em http://www.ucm.es/info/especulo/cajetin/ abreviat.html; acesso em 18/06/2006]

HRÓARSDOTTIR, T. Language change and language acquisition. Nordlyd, Troms $\emptyset$, v. 31, n. 1, p. 116-131, 2003.

KROCH, A. Reflexes of grammar in patterns of language change. Language Variation and Change, Philadelphia, v. 1, p. 199-244, 1989.

KROCH, A. Syntactic change. In: BALTIN, M.; COLLINS, C. (Eds.) The handbook of contemporary syntactic theory. Cambridge, MA: Blackwell, 2001. [Trad. port: Mudança sintática. Trad. de Sílvia Regina Cavalcante, 2003. Disponível em ftp://babel.ling.upenn.edu/facpapers/tony_kroch/ papers/mudanca-sintatica.pdf; acesso em 05.11.2012]

LABOV, W. Sociolinguistic patterns. Philadelphia: University of Pennsylvania Press, 1972.

LABOV, W. Building on empirical foundations. In: LEHMANNN, W.; MALKIEL, Y. (Eds.) Perspectives on historical linguistics. Amsterdam: John Benjamins, 1982. p. 79-82.

LABOV, W. Principles of linguistic change: internal factors. Oxford: Blackwell, 1994.

LIGHTFOOT, D. How to set parameters: arguments from language change. Cambridge, MA: MIT Press, 1991.

LIGHTFOOT, D. The development of language: acquisition, change and evolution. Massachusetts: Blackwell, 1999.

MARCOS, P. Dois perdidos numa noite suja. São Paulo: Global, 1978.

MOREIRA, J. C. O vocativo no português brasileiro no século XIX eXX: um estudo de mudança linguística. Dissertação (Mestrado) - Universidade Federal de Minas Gerais, Belo Horizonte, 2008. 
PENA, M. O noviço. In: PENA, M. Teatro de Martins Pena. Ed. crítica de Darcy Damasceno. Rio de Janeiro: Ediouro, 1956. p. 293-335.

RAMOS, J. M. O emprego de preposições no português do Brasil. In: TARALLO, F. (Org.) Fotografias sociolinguísticas. Campinas: Pontes, 1989. p. 83-93.

RAMOS, J. M. Teoria do caso e mudança linguística: uma abordagem gerativo-variacionista. Tese (Doutorado) - Universidade Estadual de Campinas, Campinas, 1991.

TARALLO, F.; KATO, M. A. Harmonia trans-sistêmica: variação intra- e interlingüística. Preedição, Campinas, v. 5, p. 1-41, 1989.

TARALLO, F. Relativization strategies in Brazilian Portuguese. Tese (Doutorado) - University of Pennsylvania, Philadelphia, 1983.

TARALLO, F. The filling of the gap: pro-drop rules in Brazilian Portuguese. In: KING, L. D. \& MALEY, C. A. (Eds.) Selected papers from the XIIIth Linguistic Symposium of Romance Languages. Amsterdam/ Philadelphia: John Benjamins, 1985. p. 354-375.

TARALLO, F. Diagnosticando uma gramática brasileira: o português d'aquém e d'além mar ao final do século XIX. In: ROBERTS, I. \& KATO, M. Português brasileiro: uma viagem diacrônica. Campinas: Ed. da UNICAMP, 1993. p. 69-102.

WEINREICH, U.; LABOV, W.; HERZOV, M. Empirical foundations for a theory of language change. In: LEHMANN, W.; MALKIEL, Y. (Eds.) Directions for historical linguistics. Austin: University of Texas Press, 1968. p. 97-189.

Recebido para publicação em 31 de julho de 2012 Aprovado em 05 de novembro de 2012 